\title{
Alaeddin Yalçınkaya ve Derya Tuğlu, Avrasya Stratejileri: Illişkiler, Örgütler, Politikalar, Ankara: Astana Yayınları, 2020, 413 s. ISBN: 978-605-5010-29-4
}

\author{
Mehmet Serhan KAPLAN ${ }^{1}$ [C]
}

'Sorumlu yazar/Corresponding author: Mehmet Serhan Kaplan,

(Yüksek Lisans Öğrencisi),

Istanbul Üniversitesi, Sosyal Bilimler Enstitüsü,

Türkiyat Araştırmaları Anabilim Dalı

E-posta:kaplanzade@outloook.com

ORCID: 0000-0002-3604-4318

Başvuru/Submitted: 09.01.2021

Kabul/Accepted: 12.01.2021

Atıf/Citation: Kaplan, Mehmet Serhan. "Avrasya

Stratejileri: Ilişkiler, Örgütler, Politikalar, adlı eserin tanıtımı. Avrasya Incelemeleri Dergisi

- Journal of Eurasian Inquiries 10, 1 (2021):

197-202.

https://doi.org/10.26650/jes.2021.010

\section{AVRASYA STRATEJILERI}

\section{İligkiler}

Örgütler

\section{Politikalar}

Editörler:

Alaeddin Yalçınkaya

Derya Tuğlu

\section{astand}

yayınlari

Avrasyacılık, Rus Çarlığı'nın ve Sovyetlerin dağılma döneminde Rusya merkezli jeopolotiğin üstünlüğünü koruma ve güçlendirme stratejisi olduğu halde günümüz şartlarında ilave anlamlar kazanmıştır. Soğuk Savaş sonrası uluslararası sistemin ABD önderliğinde "tek dünyacılığa" evrilmesi, dağılan Sovyetler Birliği sonrasında 1990'lar boyunca Rusya Federasyonu'nun da parçalanma sinyallerini vermesi, Rus aydınını yeni arayışlara itmiştir. Moskova merkezli bir Rus devletinin süper güç olmasının tehlikeli bir hayalcilikten ibaret olduğunu savunup tek çarenin ABD önderliğinde Batı'nın talimatlarını uygulamak olduğunu savunan liberaller yanında eski toprakları geri almak ve korumak için daha fazla güç ve şiddet kullanmanın gerekliliğini söyleyen Rus milliyetçileri veya komünistleri de bulunmaktaydı. Avrasyacılar ise çözüm yolu olarak şunu önermişlerdir: Eski topraklarda egemenlik kurmadan, Çarlık ve Sovyet 
rejimlerindeki baskıcı hataya düşmeden, başta Sovyet coğrafyası olmak üzere Avrasya'daki devletleri ekonomik sistem, siyasal rejim, din, dil ve kültürel alanlarda olabildiğince özgür olmalarını kabul etmek, ancak genel stratejik konularda ABD’nin güdümüne girmelerini engellemek, Rusya'nın çıkarlarına halel getirmemek, kısaca NATO ve AB'nin genişlemesini, ABD'nin yeni nüfuz bölgeleri kurmasını önlemek. 1990'lar Rusya Federasyonu'nu hedef alan iç çatışmalara karşı mücadele ile geçtiği halde 2000'ler, Balkanlar ve Kafkasya'da Atlantikçi genişlemeye karşı mukavemete sahne olmuştur. Renkli devrimler ile Sovyet coğrafyasında ABD destekli yönetimlerin iktidara gelmesi bir aşama sonra yaygın tepkiye sebep olmuş, Rusya'nın karşı saldırıya geçmesinin meşruiyet kaynağı haline gelmiştir. 2010'larla başlayan Arap Baharı süreci ise başlangıçta Tunus, Mısır ve Libya'da siyasi iktidarları devirmede başarılı olmuş, ancak siyasi istikrar ve güvenlik eskisinden daha kötü hale gelmiştir. Arap Baharı'nın daha ilk yılında elde edilen bazı “başarılara” karşın Suriye'de kilitlenme sözkonusu olmuş, 2018 başı itibariyle bu ülkedeki iç savaş ve belirsizlik sürmektedir. Bu durum önemli ölçüde Rusya'nın eski etkinlik bölgelerini yeniden ele geçirme ve ABD’nin yayılmacı stratejisini başarısız kılma politikalarının sonucudur. Bu bağlamda Rusya ve Çin öncülüğünde örgütlenmelere gidilmiş, Rusya, birçok bölgesel çatışmalardan güçlenerek çıkmış, "Yakın Çevre" ülkelerine yeniden "güçlü Rusya" mesajı verilmiştir.

2016-2017 öğretim yılında Marmara ve Bahçeşehir üniversitelerinde Avrasya Stratejileri ile Kafkasya ve Orta Asya Politikaları başlıklı lisansüstü programlarda Avrasyacılık stratejisi tarihi ve kavramsal boyutları yanında sözkonusu stratejinin günümüz politikalarında, ilişkilerinde, örgütlenmelerindeki yansımaları çalışma konuları olarak öğrencilere dağıtılmıştır. Sözkonusu çalışmalar içerisinde seçilenler edisyon sürecinden sonra bu kitapta toplanarak bu alandaki eksikliğin giderilmesi hedeflenmiştir. Alaeddin Yalçınkaya ve Derya Tuğlu'nun editörlüğünde yayımlanan Avrasya Stratejileri: Ilisşkiler, Örgütler, Politikalar kitabında yer alan makaleler şunlardır:

- Derya Tuğlu, Avrasyacılığın Tarihsel Gelişimi, s.11-23

- Yasemin Uğur Çam, Avrasya Bölgeselciliğinde Örgütlerin Rolünü Anlamak: Bağımsız Devletler Topluluğu Örneği, s.23-47

- Gökhan Katıtaş, Avrasya Ekonomik Birliği: Beklentiler ve Gerçekleşenler, s.47-83

- $\quad$ Derya Tuğlu, Avrasya Ekonomik Birliği ve Türkiye, s.83-107

- Önder Kara, Kolektif Güvenlik Antlaşması Örgütü ile Nato’nun Karşılaştırılması, S.107-129

- $\quad$ Alaeddin Yalçınkaya, Abdullah Nur Heyle, Rusyanın Ortadoğu ve Kuzey Afrika Politikas1, s.129-147

- $\quad$ Ahmet Demir, Serkan Sayan, Rasyonel Dostlar: Rusya, İran ve Suriye, s.147-179

- Ali Dönmez, Avrasya'daki Enerji Savaşlarında Çin'in Stratejileri: Çin-Kazakistan Enerji İlişkileri, s.179-201

- Susana Askarova, Çin'in Enerji Politikaları, s.201-225 
- Gökhan Katıtaş, Turgay Çölcü, Çin'in Avrasya'ya Yönelik Enerji Politikaları, s.225261

- Nur Aslan, Şanghay İşbirliği Örgütü: İç İhtilaflar ve Türkiye’nin Olası Konumu, S.261-281

- Deniz İstikbal, Yükselen Bir Güç Şangay İşbirliği Örgütü ve Türkiye, s.281-305

- $\quad$ Uğur Gül, Enerji Koridoru Olma Yolunda Tanap ve Türk Akımı Projeleri, s.305-327

- $\quad$ Emine Sezen Diler, Ermenistan ve Gürcistan İlişkileri, s.327-353

- $\quad$ Arzu Özgünay, Abhazya Tarihi Ve 2008'den İtibaren Abhazya Gelişmeleri, s.353-365

- Cavid Süleymanlı, Alaeddin Yalçınkaya, Hazar'ın Hukuki Rejimi ile İlgili Tartışmalar, s.365-391

- Gökhan Katıtaş, Saico Umaro Embalo, Özbekistan Cumhuriyeti’nde Din-Siyaset İlişkisi Ve İslam İşbirliği Teşkilatı, s.391-408

Kitabın ilk bölümünde, kitabın editörlerinden Derya Tuğlu “Avrasyacılı̆̆ın Tarihsel Gelişimi”ni adlı makalesinde jeopolitik kavramının ortaya çıkmasının Avrasyacılık açısından öneminin değerlendirmesini yapmaktadır. Makalede günümüz Avrasyacılığının uluslararası sistemdeki yeri ile büyük güçlerin bu stratejideki politika ve uygulamaları tartışılmaktadır.

Yasemin Uğur Çam, “Avrasya Bölgeselciliğinde Örgütlerin Rolünü Anlamak: Bă̆ımsız Devletler Topluluğu” başlıklı bölümde, günümüz politikalarını açıklamada önemi gittikçe artan "bölgeselcilik" kavramı çerçevesinde konuya yaklaşmaktadır. Bu kapsamda BDT'nun SSCB’nin kansız bir şekilde dağılmasına aracı olan bir örgütün ötesine geçtiği, Putin iktidarıyla Sovyet sonrasının sorunlu bir aşamasından eski cumhuriyetleri yeniden bir arada tutma zeminine dönüşümü değerlendirilmektedir. Böylece BDT’nin Avrasya Bölgeselciliğinin zemini olduğu sonucuna varılmaktadır. Bu süreçte gerek Moskova'dan uzaklaşmak isteyenlerin bu örgütten ayrılmaları gerekse Çin'in de öncülerinden olduğu Şanghay İşbirliği Örgütü zeminindeki politikaların BDT’yi zorladığı üzerinde durulmaktadır.

“Avrasya Ekonomik Birliği: Beklentiler ve Gerçekleşenler” başlıklı bölümde Gökhan Katıtaş, Avrasyacı stratejilerin en somut uygulama alanı olarak görülen Avrasya Ekonomik Birliği’ni ele almaktadır. Entegrasyonun ilk aşamalarını tamamladıktan sonra 2015 itibariyle Ekonomik Birlik aşamasına geçildiği kabul edilen örgütün sözkonusu entegrasyonda ne derece başarılı olduğu tartışılmaktadır. Moskova merkezli yeni bir “AB” olarak tasarlandığı halde başta Rusya olmak üzere örgüte üye ülkelerin farklı beklentileri, ekonomik entegrasyonun gerektirdiği ekonomik, sosyal ve hukuksal altyapı yetersizliklerine karşın böyle bir örgütlenmenin gerekliliğine dair ortak irade, karşılaşılan sorunlar ve sonuçları, bu bölümün temel sorununu oluşturmaktadır.

“Avrasya Ekonomik Birliği ve Türkiye” başlıklı bölümde Derya Tuğlu, bu birliği ele alırken konuyu, Türkiye-AB ilişkilerindeki tıkanıklığın yolaçtığı arayışlar açısından değerlendirmektedir. Son yıllarda AB yerine Şanghay İşbirliği Örgütü’ne üyelik tartışmaları yaşanırken Şanghay merkezli örgütün AB' den farklı olarak daha çok bir siyasi zemin olduğu, fakat Avrasya Ekonomik Birliği'nin başarısız da olsa AB'ye alternatif hedefleri bulunduğu dile getirilmektedir. Başta 
Rusya olmak üzere bu birlik üyesi ülkelerle ticaret hacmi ve sektörleri dikkate alındığında Türkiye'nin AB yerine Avrasya Ekonomik Birliği'ne üyeliğinin artıları ve eksikleri bu bölümde tartışılmaktadır.

Önder Kara, "Kolektif Güvenlik Antlaşması Örgütü (KGAÖ) ile NATO’nun Karşılaştırılması", başlıklı bölümde, Avrasyacı stratejilerin diğer bir somut uygulaması olarak sözkonusu örgütü ele almaktadır. Sovyet döneminin Varşova Paktı'nın dağılmasından sonra askeri alanda liderlik zemini kalmayan Moskova'nın başlangıçta eski Sovyet cumhuriyetleriyle mevcut savunma ilişkileri kapsamındaki sorunları çözmek üzere oluşturulan örgütün Putin ile Avrasyacı hedeflerin aracı haline gelmesi anlatılmaktadır. Buna karşın NATO ve Varşova Paktı, Soğuk Savaş döneminin rakip askeri örgütleri olduğu halde günümüzde bu rekabet ilişkisinin NATO ile KGAÖ arasındaki boyutları tartışılmaktadır.

Abdullah Nur Heyle ve Alaeddin Yalçınkaya'nın birlikte hazırladığı “Rusya 'nın Ortadoğu ve Kuzey Afrika Politikası” başlıklı bölümde, Avrasyacı stratejilerin Avrupa Asya'nın ötesinde Afrika boyutu ele alınmaktadır. Sovyetler Birliği’nin dağılmasından sonra Rusya Federasyonu'nun dahi dağılması problemleriyle uğraşan Moskova yönetimi, Putin ile birlikte Ortadoğu ve Kuzey Afrika'da yeniden etkinlik kurma arayışlarına girmiştir. Başlangıçta Ortadoğu ülkelerinden Çeçen direnişine gelen desteği kesmeyi hedefleyen ilişkiler, İslam İşbirliği Teşkilatı'nda gözlemci üye statüsü kazanma, bölge ülkeleriyle her alanda ilişkiler kurma, nihayet Arap Baharı sürecindeki müdahaleler ile Suriye'nin geleceğini belirlemede birincil aktör durumuna gelme politikaları bölümün temel konusudur.

Ahmet Demir ve Serkan Sayan'ın hazırladığı "Rasyonel Dostlar: Rusya, Iran ve Suriye” başlıklı bölüm, önceki bölümün devamı niteliğinde olup Avrasyacı stratejilerin Ortadoğu ve İslam dünyası boyutunu ele almaktadır. İran, Yeni Avrasyacılık stratejisinin güney vektörünü oluşturduğu halde Suriye iç savaşıyla birlikte bu teorik tanımlama son derece başarılı uygulama zemini bulmuştur. Bu süreçte Rusya'nın Suriye coğrafyasında, dolayısıyla Doğu Akdeniz'de varlığını güçlendirmesi, yeni üsler inşa etmesi ile Ortadoğu'da askeri ve siyasi bakımdan etkinlik kurması, tarihi dayanaklarıyla birlikte ele alınmaktadır. Bu bağlamda Arap Baharı ile Suriye'nin parçalanma sürecine girmesi, reelpolitik firsatları değerlendiren Putin ile Rusya'nın güçlü bir şekilde bölgeye dönüşüne vesile olduğu görülmektedir.

“Avrasya'daki Enerji Savaşlarında Çin'in Stratejileri: Çin-Kazakistan Enerji İlişkileri”, başlık bölümde Ali Dönmez, konuyu Avrasya stratejilerinin merkezinde yer alan enerji faktörü açısından ele almaktadır. Rusya ve Kazakistan, enerji ihracatçısı olduğu halde yükselen güç olarak Çin'in en büyük ithalatçı olarak Avrasyacı politikalarda önemi büyüktür. ABD karşıtı en önemli örgütlenme durumundaki Şanghay İşbirliği Örgütü’nün iki temel gücü Rusya ve Çin arasında yer alan Kazakistan'ın iki ülke arasındaki çelişkilerde izlenen pozisyonu da önemlidir. Bu bağlamda, petrol ve doğalgaz boru hatları, enerji stratejileriyle birlikte ilgili ülkelerin ekonomik olduğu kadar siyasi geleceklerini belirleyen önemli bir faktör olduğu dikkate alınarak Kazakistan-Çin ilişkileri tahlil edilmektedir. 
Susana Askarova, “Çin'in Enerji Politikalarl” başlıklı bölümde, önceki bölümün devam olarak enerji ithalatçısı ülke olarak bu yükselen gücün bölge politikaları üzerindeki etkinliğini ele alınmaktadır. ABD hegemonyasına karşı bir dereceye kadar tek/birincil alıcı pozisyonunda olan Çin'in Orta Asya, Afrika ve genel olarak Avrasya'daki etkinliği tartışılmaktadır. Bu bağlamda enerji ihracatçısı diğer Orta Asya ülkeleriyle boru hatları ve enerji ithalatı üzerinden ilişkileri geliştirirken bölgesel kalkınma ve istikrarı önceleyen politikalarla ABD’ye müdahale yollarının kapatılması tartışılmaktadır.

“Çin 'in Avrasya'ya Yönelik Enerji Politikalarl” başlıklı bölümde Gökhan Katıtaş ve Turgay Çölcü, önceki bölümlerin devamı olarak Çin'in enerji yatırım ve ticareti üzerinden bölgede etkinlik kurmasını ele almaktadırlar. Ucuz işgücü ile hızla büyüyen ekonomisi sayesinde yükselen güçlerin başına yer alan Çin'in, Moskova merkezli Avrasya stratejileri konusunda ilgisiz kalması beklenemez. Her ne kadar diğer zeminlerde Atlantikçi güçlere karşı Rusya ile işbirliği sözkonusu ise de yanıbaşındaki Orta Asya'da aynı ülke ile önemli rekabet konuları bulunmaktadır.

Nur Aslan, “Şanghay İşbirliği Örgütü: Iç̧ İhtilaflar ve Türkiye’nin Olası Konumu” başlıklı çalışmasında, Atlantikçi cephe karşısında en önemli örgüt durumundaki Şanghay İşbirliği Örgütü'nü ele almaktadır. SSCB'nin dağılmasıyla uluslararası sistem tek kutuplu olarak, Amerikan hegemonyasına girdiği halde Rusya ve Çin'in buna karşı ortak bir örgütleşmeye gitmesi önemlidir. Çalışmada bu örgütlenme aşamaları özetlenirken Çin-Rusya çelişkileri farklı açılardan ele alınmakta, bu bağlamda AB ile ilişkilerdeki olumsuzluk karşısında Türkiye'nin bu örgütle mevcut ve muhtemel ilişkileri tartışılmaktadır.

“Yükselen Bir Güç: Şanghay Işbirliği Örgütü ve Türkiye” başlıklı bölümde Deniz İstikbal, yukarıda bölümün devamı niteliğinde sözkonusu örgüt ile Türkiye ilişkilerini tahlil etmektedir. Bu bölümde Türkiye ve Şangay İşbirliği Örgütü arasındaki işbirliği ve bu örgütün Türkiye açısından Batı'ya karşı bir alternatif olup olamayacağı tartışılmaktadır. Türkiye’nin bu konudaki girişimleri ile mevcut ilişkilerin mahiyeti, resmi statüsü incelenmektedir.

"Enerji Koridoru Olma Yolunda TANAP ve Türk Akımı Projeleri” başlıklı bölümde, Uğur Gül, Avrasyacı stratejilerin Türkiye boyutunun somutlaştığı boru hatları projelerini ele almaktadır. Türk Avrasyacılığının somutlaştığı projelerden Azerbaycan-Türkiye arasındaki boru hatları yanında Rusya'dan Türkiye'ye enerji kanallarının niteliği ve politik anlamı son derece önemlidir. Bu bağlamda Rusya ile ilişkilerin bozulduğu dönemlerde Moskova yönetiminin enerji silahını koz olarak kullanmasının faturası ağır olmuş, buna karşın bütün riskleri üzerine alarak Türkiye'ye ve Türkiye üzerinden Avrupa'ya gaz sevkiyatı için Türk akımı projesini gündeme getirmiştir. Her iki projede de önemli aşamalar geçilmiştir.

Emine Sezen Diler, "Ermenistan ve Gürcistan Illişkileri” başlıklı çalışmasında Avrasya stratejilerinin jeostratejik merkezi durumundaki Kafkasya'nın bu iki eski Sovyet cumhuriyeti arasındaki ilişkileri ele almaktadır. Gürcistan, Sovyet sonrasında daha çok Moskova karşıtı politikaları benimsediği halde Ermenistan'ın Rus uydusu haline gelmesinin iki komşu ilişkilerine de önemli yansımaları sözkonusudur. Bunun yanında iki ülke ilişkilerinde önemli ölçüde 
diğer komşular Azerbaycan, İran ve Türkiye politikalarının yansımaları sözkonusudur. Bu bağlamda Ermenistan-Gürcistan ilişkileri, jeopolitik şartların da etkisiyle Avrasya stratejilerinin "inceldiği”" bir noktada yer almaktadır.

“Abhazya Tarihi ve 2008'den Itibaren Abhazya Gelişmeleri” başlıklı makalesinde Arzu Özgünay, Sovyet sonrası Rusya'nın bağımsız bir ülkeye karşı sıcak çatışmaya girdiği ilk örnek durumundaki 2008 Gürcistan müdahalesi ve sonuçlarını ele almaktadır. Avrasyacı stratejiler bağlamında Atlantikçilere, ABD’ye yakınlığı ile dikkat çeken Gürcistan'ın parçalanması gerektiği daha 1990'ların sonunda dile getirilmektedir. 2008'e gelindiğinde bu politika hayata geçirilmiş ve Güney Osetya ile birlikte Abhazya Rusya'nın müdahalesi ile fiilen bağımsızlaştırılmıştır.

Cavit Süleymanlı ve Alaeddin Yalçınkaya "Hazar'ın Hukuki Rejimi ile İlgili Tartışmalar" başlıklı bölümde, Sovyetlerin dağılması ile kıyıdaş ülke sayısının ikiden beşe çıktığı Hazar'ın statüsü sorununu ele almaktadır. Statü konusunun sorun haline gelmesinde İran'ın çıkarları ön planda görülmektedir. Bununla beraber geçen süre zarfında sorunun çözülememesi, başta Bakü-Tiflis-Ceyhan boru hattı olmak üzere Moskova merkezli Avrasya stratejilerine aykırı kabul edilen politikaları yüzünden Azerbaycan'ın bir bakıma cezalandırılması sözkonusudur. Makalede sorunun tarihi seyri özetlenerek son gelişmeler değerlendirilmektedir.

Gökhan Katıtaş ve Saico Umaro Embalo'nun ortak hazırladıkları “Özbekistan Cumhuriyeti'nde Din-Din Siyaset İlişkisi ve İslam İşbirliği Teşkilatı” başlıklı bölümde, Orta Asya’nın merkez ülkesi durumundaki Özbekistan'da bağımsızlık sonrası ilişkiler ele alınmaktadır. Öncelikle İslam tarihinde Özbekistan coğrafyasının önemi anlatılmakta, daha sonra İslam İşbirliği Teşkilatı'nın kuruluşu ve faaliyetleri özetlenmektedir. Ardından bağımsızlık sonrası Kerimov yönetiminin katı politikaları ile radikalleşme sürecine giden yol değerlendirilmektedir.

Özetle kitapta, ilk bölümler öncelikle Avrasyacılık kavram, tarih ve kurumları kapsamındaki bölümlere ayrılmış, daha sonraki bölümler ise bu çerçevedeki politikalarla ilgili bölgesel ve ülkesel sorunlar ve konulara ayrılmıştır. Gerek Avrasyacılık kapsamındaki farklı ülkelerin ve düşünürlerin yaklaşımları gerekse bu alandaki örgütlenmeler, ilişkiler, sorunlar ve konular çok daha geniştir. Kitabın içinde bulunan kısımlar şunlardır:

Sonuç olarak eser, günümüzde Avrasyacılık eksenli yeni dünya düzenini incelemeyi merkeze alarak farklı yazarların farklı bakış açısıyla makaleler şeklinde tasarlanmış ve her bölümün kaynakçası, kitabın sonundaki "notlar" başlığı altında ayrıca verilmiştir. Dipnotların kitabın arkasında verilmesi, açıp bakmayı zorlaştırsa da daha akıcı ve kesintisiz bir okumayı bizlere sunduğu da ortadadır. Son kısımda, verilen makaleler ve web siteleri konuda uzmanlaşmak isteyen insanlar için adeta bir yönlendirici yardımcı vazife görmektedir. Ayrıca Şangay İşbirliği Örgütü üzerinden ülkemizin bu eksende var olup olamayacağ 1 tetkik edilmiştir. Okuyucularda bu kısımlar Türkiye'nin Avrasya ekseninde yerinini olup olmayacağı konusunda derin bir düşünce içerisine girmektedir. Ufak tefek imla hataları dışında eserde genel bir olumsuz durum bulunmamakta olup okunuş açısından akıcıdır. Kitapta yer alan her bölüm sonundaki kaynaklar listesi, bu konuda da araştırmacı ve okuyuculara yol göstermektedir. Avrasyacılık alanında çalışmak isteyenler için faydalı ve yeni bakış açıları kazanmayı sağlayacak verimli bir kitaptır. 